\title{
Microvascular Decompression for Geniculate Neuralgia through a Retrosigmoid Approach
}

\author{
Vincent N. Nguyen $^{1} \quad$ Jaafar Basma ${ }^{1} \quad$ Jeffrey Sorenson ${ }^{1} \quad$ L. Madison Michael II ${ }^{1}$ \\ ${ }^{1}$ Department of Neurosurgery, University of Tennessee, Memphis, \\ Tennessee, United States \\ J Neurol Surg B 2019;80(suppl S3):S322. \\ Address for correspondence L. Madison Michael II, MD, Department \\ of Neurosurgery, University of Tennessee, 847 Monroe Avenue Suite \\ 427, Memphis, TN 38163, United States \\ (e-mail: mmichael@semmes-murphey.com).
}

\begin{abstract}
Keywords

- cerebellopontine angle

- microvascular decompression

- geniculate neuralgia

- nervus intermedius

- facial nerve

- internal auditory meatus

- microsurgery

- retrosigmoid approach

- glossopharyngeal nerve

- vagus nerve

Objectives To describe a retrosigmoid approach for the microvascular sectioning of the nervus intermedius and decompression of the 5th and 9th cranial nerves, with emphasis on microsurgical anatomy and technique.

Design A retrosigmoid craniectomy is performed in the lateral decubitus position. The dura is opened and cerebrospinal fluid (CSF) is released from the cisterna magna and cerebellopontine cistern. Dynamic retraction without rigid retractors is performed. Subarachnoid dissection of the cerebellopontine angle exposes the 7th to 8th nerve complex. A neuromonitoring probe is used with careful inspection of the microsurgical anatomy to identify the facial nerve and the nervus intermedius as they enter the internal auditory meatus. The nervus intermedius is severed. A large vein coursing superiorly across cranial 9th nerve was coagulated and cut. A Teflon pledget is inserted between a small vessel and the 5th nerve. Photographs of the region are borrowed from Dr. Rhoton's laboratory to illustrate the microsurgical anatomy.

Participants The senior author performed the surgery. The video was edited by Drs. V.N. and J.B.

Outcome Measures Outcome was assessed by postoperative neurological function. Results The nervus intermedius was successfully cut and the 5th and 9th nerves were decompressed. The patient's pain resolved after surgery and at later follow-up.

Conclusions Understanding the microsurgical anatomy of the cerebellopontine angle is necessary to identify the cranial nerves involved in facial pain syndromes. Subarachnoid dissection and meticulous microsurgical techniques are key elements for a successful microvascular decompression.

The link to the video can be found at: https://youtu.be/pV5Wip7WusE.
\end{abstract}

Conflict of Interest

None declared.

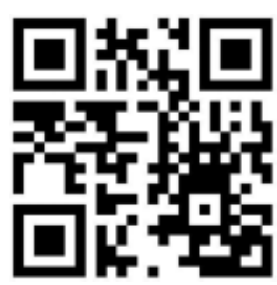

received

June 2, 2018 accepted after revision November 11, 2018 published online December 24, 2018 www.thieme.com/skullbasevideos

www.thieme.com/jnlsbvideos
License terms

c) $(1) \$$
DOI https://doi.org/

10.1055/s-0038-1676837. ISSN 2193-6331. (c) 2019 Georg Thieme Verlag KG Stuttgart · New York 